\title{
THE ROLE OF SCLEROSTIN AND PGC-1 ALPHA IN THE PATHOGENESIS OF OSTEOPOROSIS
}

\author{
Armine V. GRIGORYAN ${ }^{1 凶}$, Tatyana M. BETOVA ${ }^{2}$, Theresa B. DINEVA ${ }^{2}$, Savelina L. \\ POPOVSKA ${ }^{2}$, Radoslav G. TRIFONOV ${ }^{3}$, Aneliya A. DIMITROVA ${ }^{1}$ \\ ${ }^{1}$ Department „Physiology and Pathophysiology“, Medical University-Pleven, Bulgaria \\ ${ }^{2}$ Department „General and Clinical Pathology“, UMHAT „Dr Georgi Stranski“-Pleven, Bulgaria \\ ${ }^{3}$ Medical University-Pleven, Bulgaria
}

Received 06 Apr 2020, Accepted 05 May 2020
htps://doi.org/10.31688/ABMU.2020.55.2.11

\begin{abstract}
Introduction. Canonical Wnt signaling pathway regulates stromal stem cells (SSCs) differentiation and controls the balance between adipogenesis and osteogenesis. Estrogen deficiency affects Wnt signaling by altering the expression of sclerostin (SCL) and the peroxisome proliferator-activated receptor- $\gamma$ coactivator 1- $\alpha$ (PGC-1 $\alpha$ ) in the bone tissue.

The objective of the study was to monitor whether there is a feedback mechanism between SCL and PGC-1 $\alpha$ and to determine the extent of the immunohistochemical staining of PGC-1 $\alpha$ and SCL in bone tissue of estrogen deficiency-induced osteoporosis in female Wistar rats.
\end{abstract}

Materials and methods. An experiment was performed on 20 female Wistar rats at reproductive age (2 months), divided into 2 groups: in group 1 (G1) 10 animals were ovariectomized (ovx) and in group 2 (G2) 10 of the remaining were sham-operated (sham).

Results. We found that the PGC-1 $\alpha$ in the bone marrow stromal cells was reduced in the group with osteoporosis (G1 - ovariectomized rats), compared to sham-operated control group G2 $(p<0.05)$. The $\mathrm{SCL}$ in osteocytes was increased in the group with

\section{Résumé}

Le role de la sclerostine et du PGC-1 alpha dans la pathogenese de l'osteoporose

Introduction. La voie de signalisation canonique Wnt régule la différenciation des SSC et contrôle l'équilibre entre l'adipogenèse et l'ostéogenèse. La carence d'œestrogènes affecte la signalisation Wnt en modifiant l'expression de la sclérostine (SCL) et du peroxysome proliférateur-récepteur-coactivateur 1- $\alpha$ (PGC-1 $\alpha$ ) dans le tissu osseux.

Le but de l'étude était de surveiller s'il existe un mécanisme de rétroaction entre le SCL et le PGC-1 $\alpha$ et de déterminer l'étendue de la coloration immunohistochimique du PGC-1 $\alpha$ et du SCL dans le tissu osseux de l'ostéoporose induite par une carence en œstrogènes chez les rats Wistar femelles.

Matériel et méthodes. Une expérience a été réalisée sur 20 rats Wistar femelles en âge de procréer - 2 mois, divisés en 2 groupes: dans le groupe 1 (G1) 10 animaux ont été ovariectomisés (ovx) et dans le groupe 2 (G2) 10 des autres ont été simulés (sham).

Résultats. Nous avons constaté que le PGC-1 $\alpha$ dans les cellules stromales de la moelle osseuse était réduit 
osteoporosis - G1, compared to control group G2 $(\mathrm{p}<0.05)$. Histomorphological analysis of femur from G1 animals indicated reduced areas of mineralized tissue and bone marrow fatty degeneration.

Conclusions. Estrogen deficiency in G1 ovx rats increased the expression of SCL in the osteocytes by activating osteoclastic bone resorption and reduced PGC-1 $\alpha$ expression in SSCs cells, which stimulated adipogenic differentiation that led to significant fatty degeneration in the bone marrow. We confirmed the exceptional role of PGC-1a and SCL in the pathogenesis of osteoporosis and that there is a mechanism of feedback loop between SCL and PGC-1 $\alpha$.

Keywords: PGC-1 $\alpha$, sclerostin, estrogen deficiency, osteoporosis.

\author{
Abbreviations \\ PGC-1 $\alpha$ : peroxisome proliferator-activated receptor- $\gamma$ \\ coactivator $1-\alpha$ \\ SCL: sclerostin \\ SSCs: stromal stem cells \\ FD: fatty degeneration \\ IHC: immunohistochemical \\ OVX: ovariectomized rats \\ SHAM: sham-operated rats \\ H\&E: hematoxylin \& eosin staining \\ OPG: osteoprotegerin \\ RANKL: receptor activator of nuclear factor kappa-B \\ ligand
}

\section{INTRODUCTION}

Osteoporosis reflects a disruption of the bone remodeling process, bone resorption prevailing over bone formation ${ }^{1}$. Fatty bone marrow fatty degeneration (FD) is a complication characteristic of osteoporosis ${ }^{2}$. Increased bone marrow fat accumulation takes place at the expense of bone formation and in turn impairs osteogenic regeneration ${ }^{3}$. Canonical Wnt signaling pathway regulates SSCs differentiation and controls the balance between adipogenesis and osteogenesis ${ }^{4,5}$. Estrogen deficiency increases sclerostin (SCL) expression ${ }^{6}$ and reduces the expression of peroxisome proliferator receptor- $\gamma$ coactivator 1- $\alpha$ (PGC-1 $\alpha$ ) in the bone tissue ${ }^{7}$ by disrupting Wnt signaling ${ }^{8}$. Sclerostin is a secreted glycoprotein with a C-terminal cysteine knot-like domain, which is produced by the osteocytes? ${ }^{9}$. In its presence, osteoblast precursors are not affected by the Wnt signal and as a result the process of osteoblast differentiation stops ${ }^{10}$. The PGC-1 $\alpha$ is a key regulator to multiple pathways dans le groupe atteint d'ostéoporose (les animaux G1 étaient ovariectomisés), par rapport au groupe témoin G2 (p<0,05). Le SCL dans les ostéocytes a augmenté dans le groupe atteint d'ostéoporose - G1, par rapport au groupe témoin G2 ( $<<0,05)$. L'analyse histomorphologique du fémur des animaux $\mathrm{G} 1$ a indiqué des zones réduites de tissu minéralisé et une dégénérescence graisseuse de la moelle osseuse.

Conclusions. Une carence en oestrogènes chez les rats G1 ovx a augmenté l'expression de SCL dans les ostéocytes en activant la résorption osseuse ostéoclastique et en réduisant l'expression de PGC-1 $\alpha$ dans les cellules SSC, ce qui a stimulé la différenciation adipogénique qui a conduit à une dégénérescence graisseuse importante dans la moelle osseuse. Nous avons confirmé le rôle exceptionnel de PGC-1a et SCL dans la pathogenèse de l'ostéoporose et qu'il existe un mécanisme de boucle de rétroaction entre SCL et PGC-1 $\alpha$.

Mots-clés: PGC-1 $\alpha$, sclérostine, carence en œstrogènes, ostéoporose.

controlling overall energy homeostasis in the bone and adipogenesis in SSCs?

THE OBJECTIVE OF THE STUDY was to monitor whether there is a feedback mechanism between SCL and PGC-1 $\alpha$ and to determine the extent of the immunohistochemical (IHC) staining of PGC-1 $\alpha$ and SCL in bone tissue of estrogen deficiency-induced osteoporosis in female Wistar rats.

\section{Materials AND MEthods}

\section{Animals and experimental design}

The animal experiments were approved and all experiments were performed in accordance with the Guidelines of the Scientific Ethics Committees of Medical University-Pleven, Bulgaria (certificate no. 556/ 07.05.2019).

An experiment was performed on 20 female Wistar rats at reproductive age ( 2 months), divided into 2 groups: in group 1 (G1) 10 animals were ovariectomized (ovx), and in group 2 (G2) 10 of the 
remaining ones were sham-operated (sham). Animals were selected with initial weight $150 \pm 20$ grams.

A bilateral ovariectomy in female Wistar rat leads to bone changes,similar to those of postmenopausal women ${ }^{11,12}$. All rats grew in a standard manner rules of work with laboratory animals, adopted from Medical University-Pleven, Bulgaria. The animals were prepared for the experiment by acclimatization to the conditions for one week prior to the experiment. They were accommodated in an air-conditioned room (relative humidity 45-65\%) over a 12-hour light/dark cycle at $22 \pm 2^{\circ} \mathrm{C}$, with free access to food and water.

The model of osteoporosis was created according to the method of Kharode et al, 2008 ${ }^{11}$. At surgery, rats were initially anesthetized intraperitoneally with a mixture of xylazine $(10 \mathrm{mg} / \mathrm{kg})$ and ketamine $(90$ $\mathrm{mg} / \mathrm{kg}$ ).We calculated for each animal a dose of anesthesia according to their weight, which is detailed in the experimental protocol. After the double-sided ovx, muscles, fascia and skin were gradually restored. In the placebo group, the same surgical procedure was performed, but without ovariectomy. The procedure lasted approximately 10 minutes for each laboratory animal. Postoperative field was treated with an antibacterial powder and each animal was placed in an individual cell for postoperative observation and care. A high degree of aseptic procedures was maintained throughout the operation. Surgical sutures were removed 10 days after surgery ${ }^{11}$.

\section{Sampling}

After a 30-day experimental period, the animals were euthanized with an intravenous overdose of xylazine/ketamine anesthetizing cocktail. Morphological and immunohistochemical (IHC) studies were performed at the Department of Pathology at Medical University - Pleven, Bulgaria. The left femur was selected for the research. According to Fonseca et al (2012), estrogen deficiency leading to the development of osteoporosis is best observed in the proximal femur ${ }^{13}$.

\section{Morphological analysis}

The left femur of each rat was carefully prepared and explanted, which was fixed in 10\% buffered formalin (pH-7). The samples were then washed and decalcified with histological solution "Osteosoft", catalog No 1017281000, for 24-48 hrs, paraffin embedded, and sectioned. From each paraffin block, tissues were cut into successive $3 \mu \mathrm{m} \mathrm{sec-}$ tions per SHANDON microtome. Each sample was subjected to routine histological examination with Hematoxylin \& Eosin (H\&E) and IHC testing.

\section{Immunohistochemical analysis}

The following antibodies were used for IHC studies: Anti-Sclerostin antibody (ab63097), according to the manufacturer's instructions (Abgam), and PGC-1 $\alpha$ (sc-518025), according to the manufacturer's instructions (Santa Cruz Biotechnology, Inc.).

\section{Quantitative analysis}

IHC analysis performed on formalin-fixed paraffin-embedded (FFPE) tissue sections traditionally has been semi-quantified by the pathologist's visual scoring of the staining. The evaluation was performed by two independent pathologists. We used the following scale for the intensity of estimations: 0 - no coloring; 1 - weak; 2 - moderate; 3 - strong ${ }^{14}$. For the statistical processing, the nonparametric test - Mann Whitney was used, by comparing the median values via SPSS 17.0 statistical software. Data were presented as mean \pm standard error of the mean (SEM), with $p<0.05$ as the limit for statistical significance.

\section{Results}

IHC staining of PGC-1 $\alpha$ in the bone marrow SSCs was reduced in the group with osteoporosis (G1) compared to control group G2 ( $p<0.05$ ), as seen in Fig.1. Also, in G1 there were observed thin bone trabeculae, disconnected from each other, and pronounced bone marrow degeneration.

It was found that the expression of SCL in the osteocytes was increased in the group G1 compared to group G2 ( $\mathrm{p}<0.05$ ). Also, in G2 pronounced osteoclastic activity was observed (Fig 2).

Histomorphological analysis of the femurs from G1 indicated reduced areas of mineralized tissue, scant disconnected and thin bone trabeculae, and fat degeneration in the bone marrow compared to the control group, shown in Fig. 3. The pathologic changes included an increase in the proportion of adipose tissue in bone marrow, diminished hematopoiesis and an increased percentage of empty osteocyte lacunae. None of these abnormal changes were detectable in the control group. Staining with $H \& E$ showed fat cells in the bone marrow stroma of the ovx group. The number of adipocytes and FD in G1 group was higher than in group G2.

\section{Discussion}

In recent years, the Wnt signaling pathway riveted attention in connection with the discovery of its influence on the processes of formation and regeneration of bone tissue ${ }^{5}$ and therefore modulation of this path may be useful in the treatment of osteoporosis and other bone diseases. SCL inhibits 


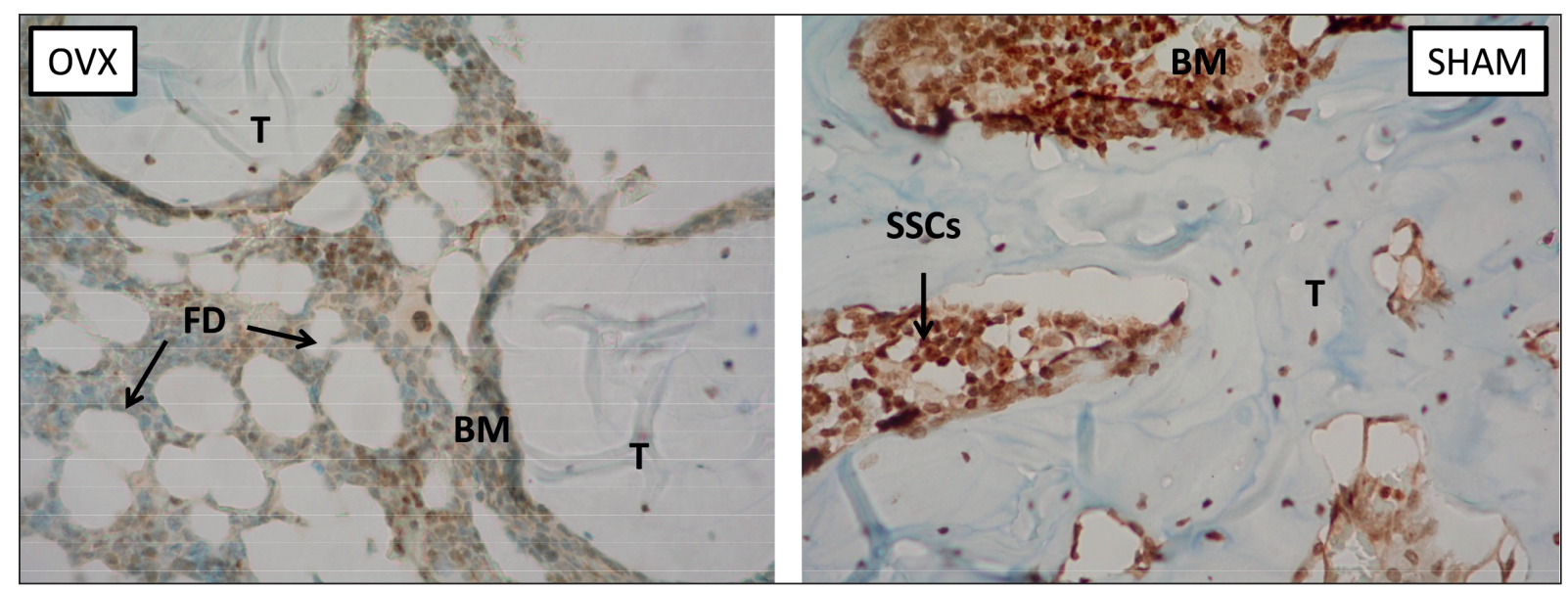

Figure 1. IHC response of PGC-1a in femur preparations. (ovx): An animal from group G1; weak immunostaining for PGC-1a in bone marrow SSCs. (sham): An animal from group G2; moderate to strong diffuse intensive immunostaining for PGC-1a in bone marrow SSCs. Brown cytoplasmic staining, Magnification x 400. T-trabeculae, BM-bone marrow, FD-fatty degeneration, SSCs - stromal stem cells.

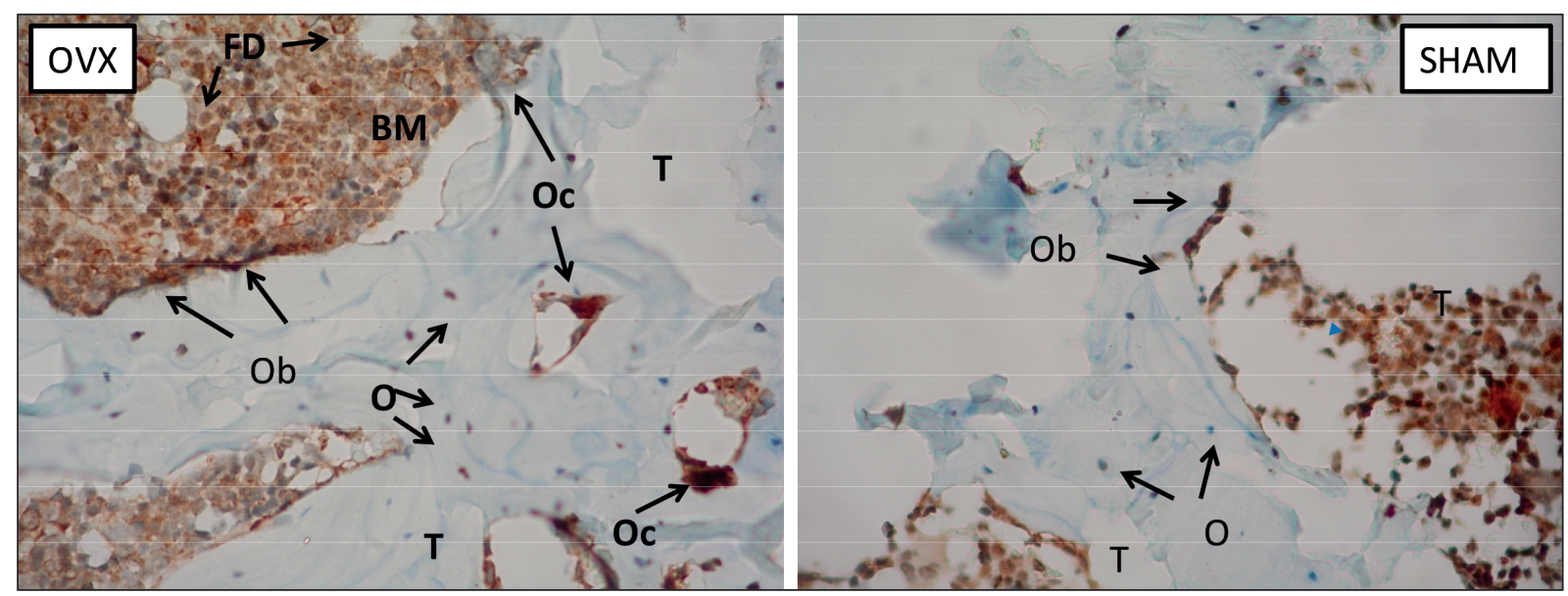

Figure 2. IHC response of SCL in femur preparations. (ovx): An animal from group G1; weak immunostaining for sclerostin in a few osteocytes. (sham): An animal from group G2; moderate to strong intensive immunostaining for SCL in plurality osteocytes. Brown cytoplasmic staining, Magnification x 400. T-trabeculae, BM-bone marrow,

FD-fatty degeneration, O-osteocyte, Ob-osteoblast, Oc- osteoclast.
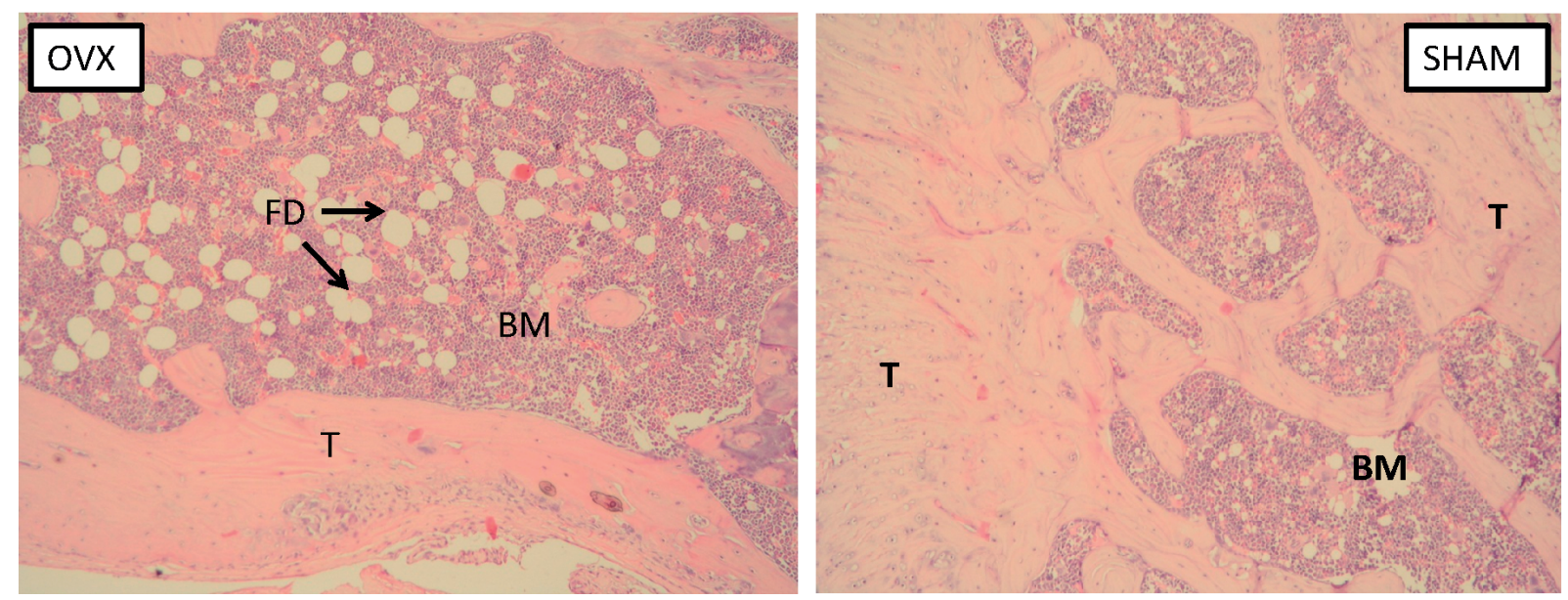

Figure 3. Hematoxylin-Eosin staining. Sampling of femoral bone preparations. (ovx): An animal from group G1; The trabecula is surrounded by fat cells; hemopoietic marrow is situated away from the bone. An area of FD consisting exclusively of fat cells is seen at the centre. Original magnification $\times 100$. T-trabeculae, BM-bone marrow, FD-fatty degeneration. (sham): An animal from group G2; Magnification x 100. 
bone formation by binding to LRP5/6 co-receptors and thereby antagonizing WNT/ $\beta$-catenin signaling in osteoblasts ${ }^{15}$. Moreover, SCL increases osteoclastogenesis by increasing RANKL and decreasing OPG expression ${ }^{16}$. We have found that expression of SCL increased after ovx and was combined with increased bone resorption in group G1 compared to control group G2. Today, treatment with sclerostin monoclonal antibodies ( $\mathrm{Scl}-\mathrm{Ab}$ ) has been shown to improve the quality of osteoporotic bone in animal models with ovx ${ }^{17,18}$. Despite a number of undesirable effects, Scl-Ab (Romosozumab) is approved for use in Japan, the USA and the European Union in 2019, as it was proven that it reduces the risk of fractures in postmenopausal women with low bone density ${ }^{19,20}$. Researchers suggest the use of a SCL vaccine against estrogen-induced bone loss. This type of immunotherapy would restore Wnt signaling ${ }^{21}$.

PGC-1 $\alpha$ plays a crucial role in bone metabolism. PGC1 $\alpha$-deficient mice display impaired bone structure, revealing that the absence of PGC1 $\alpha$ can affect the microstructural and mechanical properties of the bone ${ }^{22,23}$. It was found that PGC-1 $\alpha$ controls adipogenesis in SSCs and the loss of PGC-1 $\alpha$ disrupts bone formation in osteoporosis ${ }^{7,24}$. We found that ovariectomy led to decreased expression of PGC-1 $\alpha$, which was combined with manifested fatty bone marrow degeneration. He Yi-Xin et al (2011) proved that the adipocyte number was significantly greater in rats after ovx ${ }^{24}$. Pino et al (2012) also confirmed that estrogen deficiency switches the Wnt signaling pathway in SSCs, leading to bone marrow $\mathrm{FD}^{25}$. Chronic estrogen deficiency affects osteocyte-mediated Wnt signaling pathways, by altering the expression of PGC-1 $\alpha$ and SCL. Using Sc-AbII, scientists have demonstrated that blocking sclerostin, an inhibitor of the WNT pathway, stimulates PGC1 $\alpha$ expression ${ }^{26,27}$. Therefore, we can state that sclerostin not only leads to bone loss, but also acts as a negative regulator of PGC-1 $\alpha$.

\section{Conclusions}

PGC-1 $\alpha$ has anabolic and Sclerostin has anti-anabolic effects on bone formation. Our experiment has been able to demonstrate that sclerostin down-regulates PGC-1 $\alpha$ and that there is a mechanism of feedback loop between SCL and PGC-1 $\alpha$. Estrogen deficiency in G1 ovx rats initially increased the expression of SCL in osteocytes, by activating osteoclastic bone resorption and reduced PGC-1 $\alpha$ expression in SSCs cells, which stimulated adipogenic differentiation that led to significant fatty degeneration in the bone marrow. We confirmed the exceptional role of PGC-1a and SCL in the pathogenesis of osteoporosis.

\section{Author Contributions:}

Conceptualization, A.V.G.; methodology, T.M.B., S.L.P. and T.B.D.; software, A.V.G. and R.G.T.; validation, T.M.B., S.L.P. and T.B.D.; formal analysis, A.A.D. and A.V.G.; investigation, T.M.B. and T.B.D.; resources, S.L.P.; data curation, A.A.D.; writing-original draft preparation, A.V.G.; writing-review and editing, T.M.B., R.G.T., S.L.P. and A.A.D.; visualization, A.V.G.; supervision, T.M.B. and A.A.D.; project administration, A.V.G. All the authors have read and agreed with the final version of the article.

\section{Compliance with Ethics Requirements:}

„The authors declare no conflict of interest regarding this article."

„The authors declare that all the procedures and experiments of this study respect the ethical standards in the Helsinki Declaration of 1975, as revised in 2008(5), as well as the national law."

\section{Acknowledgements:}

Special thanks to Medical University - Pleven for funding project 7/2019.

\section{References}

Black D, Clifford R. Postmenopausal osteoporosis. New England Journal of Medicine. 2016;374(3):254-262.

Schwartz A. Marrow fat and bone: review of clinical findings. Frontiers in Endocrinology. 2015;6:40.

Ambrosi T H, Scialdone A, Graja A, et al. Adipocyte accumulation in the bone marrow during obesity and aging impairs stem cell-based hematopoietic and bone regeneration. Cell Stem Cell. 2017;20(6):771-784.

Matsushita Y, Nagata M, Kozloff K, et al. A Wnt-mediated transformation of the bone marrow stromal cell identity orchestrates skeletal regeneration. Nature Communications. 2020;11(1):1-17.

Leucht P, Sooyeon L, Nury Y. Wnt signaling and bone regeneration: Can't have one without the other. Biomaterials. 2019;196:46-50.

Kim BJ, Bae S, Lee S, et al. TNF- $\alpha$ mediates the stimulation of sclerostin expression in an estrogen-deficient condition. Biochemical and Biophysical Research Communications. 2012;424(1):170-175.

Yu B, Huo L, Liu Y, et al. PGC-1 $\alpha$ controls skeletal stem cell fate and bone-fat balance in osteoporosis and skeletal aging by inducing TAZ. Cell Stem Cell. 2018;23(2):193-209.

Xu Y, Wu C, Wu Y, et al. Epimedium-derived flavonoids modulate the balance between osteogenic differentiation and adipogenic differentiation in bone marrow stromal cells of ovariectomized rats via Wnt/ $\beta$-catenin signal pathway activation. Chinese Journal of Integrative Medicine. 2012;18(12):909-917. 
Wibmer C, Amrein K, Fahrleitner-Pammer A, et al. Serum sclerostin levels in renal cell carcinoma patients with bone metastases. Scientific Reports. 2016;6: 33551.

Abed É, Couchourel D, Delalandre A, et al. Low sirtuin 1 levels in human osteoarthritis subchondral osteoblasts lead to abnormal sclerostin expression which decreases Wnt/ $\beta$-catenin activity. Bone. 2014;59:28-36.

Kharode Y, Sharp M, Bodine P. Utility of the ovariectomized rat as a model for human osteoporosis in drug discovery. In Osteoporosis. Humana Press. 2008:111-124.

He YX, Zhang G, Pan X, et al. Impaired bone healing pattern in mice with ovariectomy-induced osteoporosis: A drill-hole defect model. Bone. 2011;48(6): 1388-1400.

Fonseca H, Moreira-Gonçalves D, Vaz M, et al. Changes in proximal femur bone properties following ovariectomy and their association with resistance to fracture. Journal of Bone and Mineral Metabolism. 2012;30(3):281-292.

Jiménez P, Piazuelo E, Sánchez M T, Ortego J, Soteras F, Lanas A. Free radicals and antioxidant systems in reflux esophagitis and Barrett's esophagus. World Journal of Gastroenterology. 2005;11(18):2697.

Appelman-Dijkstra N, Papapoulos S. Sclerostin inhibition in the management of osteoporosis. Calcified Tissue International. 2016;98(4):370-380

Wijenayaka A, Kogawa M, Lim H, Bonewald L, Findlay D, Atkins G. Sclerostin stimulates osteocyte support of osteoclast activity by a RANKL-dependent pathway. PloS One. 2011;6(10):e25900.

Ominsky M, Boyce R, Li X, Ke H. Effects of sclerostin antibodies in animal models of osteoporosis. Bone. 2017;96:63-75.

Baron R, Gori F, Leder B. Sclerostin inhibition in the treat ment of osteoporosis. In Osteoporosis. Humana, Cham. 2020:375-389.
Blakely K, Johnson C. New osteoporosis treatment means new bone formation. Nursing for Women's Health. 2020;24(1):52-57.

Langdahl B, Libanati C, Crittenden D, et al. Romosozumab (sclerostin monoclonal antibody) versus teriparatide in postmenopausal women with osteoporosis transitioning from oral bisphosphonate therapy: a randomised, open-label, phase 3 trial. The Lancet. 2017;390(10102):1585-1594.

Lian W, Ko J, Wang F. Sclerostin vaccination prevents oestrogen loss-induced osteoporosis. Orthopaedic Proceedings. The British Editorial Society of Bone E Joint Surgery. 2018;100(15):34-34.

Colaianni G, Lippo L, Sanesi L, et al. Deletion of the transcription factor PGC-1 $\alpha$ in mice negatively regulates bone mass. Calcified Tissue International. 2018;103(6):638-652.

Abdel-Daim MM, Shaheen HM, Abushouk AI, et al. Thymoquinone and diallyl sulfide protect against fipronil-induced oxidative injury in rats. Environmental Science and Pollution Research. 2018;25(24):23909-23916.

He Y, Zhang G, Pan X, et al. Impaired bone healing pattern in mice with ovariectomy-induced osteoporosis: A drill-hole defect model. Bone. 2011; 48(6):1388-1400.

Pino A M, Rosen C, Rodríguez J. In osteoporosis, differentiation of mesenchymal stem cells (MSCs) improves bone marrow adipogenesis. Biological Research. 2012;45(3): 279-287.

Artsi H, Gurt I, El-Haj M, et al. Sirt1 promotes a thermogenic gene program in bone marrow adipocytes: from mice to (wo) men. Frontiers in Endocrinology. 2019;10:126.

Khosla S, Melton III J, Riggs B. The unitary model for estrogen deficiency and the pathogenesis of osteoporosis: is a revision needed? Journal of Bone and Mineral Research. 2011;26(3):441-451. 